\title{
Motor TPL Insurance: The Case of Italy
}

\author{
Prof. Ing. Luca Rossi. \\ Università degli Studi Niccolò Cusano \\ Via Don Carlo Gnocchi, 300166 Roma
}

\begin{abstract}
This study analyzes the social impact of motor TPL insurance, focusing on direct costs. It presents the variables in motor TPL insurance and through a multiple regression model shows how they contribute to the average premium insurance. The analyses aim to: $i)$ confirm the increase of the average premium insurance when moving from Northern to Southern Italy; ii) identify the main variables related to motor TPL insurance; iii) highlight a positive relationship between motor TPL insurance average premium and car thefts. These findings confirm that lower cost of motor TPL insurance is necessary to define, in Italy, a policy that combats the phenomenon of car thefts and insurance fraud, to issue suitable guidelines for insurance companies and introduce mandatory regulations forcing companies to effectuate product reformulation.
\end{abstract}

Keywords: Motor TPL insurance; Social Costs; Bonus/malus; multiple regression models

\section{Introduction}

The analysis of motor TPL insurance has been much studied in literature being one of the important lines of insurance business, in developed and in developing countries, as well.

Part of the literature, about motor TPL insurance has investigated the legal structure in terms of changing regulation (Gönülal, 2010, Tomeski, 2012 and Bau\& Gu, 2014) giving an analysis of the advantages and disvantages as a result of turning from a state-regulated system to a liberal tariff regime for motor TPL. Other studies have focused the analysis of the average motor insurance premiums in EU member states showing like in Italy are higher than in other European Countries (Santoliquido, 2014 and Insurance Europe, 2015). The Boston Consulting group carried out an analysis of the technical reasons exploring price differences in motor insurance in various European Countries (Italy, France, Germany and Spain). This study has identified four factors that are increasing the cost of insurance in Italy: personal injury, traffic risk and driving, fraud and property damage.

\section{Italian Condition}

In Italy, guidelines for motor TPL insurance are dictated by the Ministry of Production Activities and contained in the "Private Insurance Code" consisting of 19 securities and 355 laws. Nevertheless, the regulation of this sector is constantly evolving.

Below are the two decrees of Bersani[1][2]:

- Bersani Decree - Visco [1] stipulates that for all civil liability claims that have occurred since 2007, each insurance company will be called upon to compensate its customers, damaging claim against the company if your customer does not result in charge then.

- Bersani Decree bis [2], which with a new wave of liberalization has also ruled that it is no longer possible to assign a lower class of merit than a vehicle already insured within the same family nucleus, and that the variations in malus of the classes of merit are related to the actual responsibility of the contractor [3].

These measures, according to the president of ANIA (National Association of Insurance Companies), have given considerable help to consumers in the short term, but have also created several structural problems that have seriously disadvantaged the insurance companies [4].

In addition, recent studies have shown that the insurance sector is still in crisis and insurance premiums are steadily increasing and dizzying. The causes of this, according to ANIA, are attributable to many factors: the increase in the insurance ceilings provided by European legislation; an increase in the tariff requirement resulting from the modification of the malus-bonus regulations and increasingly generous court decisions on personal 
injury. It also emerged that in Italy the frequency of claims, compared to other European countries, is particularly high just like the total cost of compensation [5].

Considering the data provided by Institute for Insurance Supervision (IVASS, [6]) on the number of policies signed in the year 2015, this paper aims to present in detail what are the variables in motor TPL insurance and, through a multiple regression model it shows how these contribute to the average premium insurance.

\section{Analysis of variables}

This section indicates which variables are to be used to calculate the insurance premium. For this scope, the document "Bollettinostatistico" provided by Insurance Supervision Institute (IVASS) which highlights the situation of motor TPL insurance in Italy in 2015 was used. In Italy, in the year 2015, a total of 7,995,744 TPL motor insurance policies were stipulated with an average premium of $439.10 €$, highlighting a strong disparity between various Italian regions. Table 1 depicts the average premium per region as well as other pertinent data.

Table 1: Situation in Italian regions, 2015

\begin{tabular}{|l|l|l|l|}
\hline Region & Average premium & Number of policies & Influence of single regions \\
\hline Abruzzo & $€ 408.20$ & 188,668 & $2.36 \%$ \\
\hline Basilicata & $€ 363.50$ & 77,272 & $0.97 \%$ \\
\hline Calabria & $€ 499.20$ & 232,160 & $2.90 \%$ \\
\hline Campania & $€ 585.90$ & 588,660 & $7.36 \%$ \\
\hline Emilia Romagna & $€ 432.90$ & 632,196 & $7.91 \%$ \\
\hline Friuli Venezia Giulia & $€ 329.80$ & 187,024 & $2.34 \%$ \\
\hline Lazio & $€ 486.60$ & 786,372 & $9.83 \%$ \\
\hline Liguria & $€ 444.80$ & 189,444 & $2.37 \%$ \\
\hline Lombardia & $€ 398.90$ & $1,361,880$ & $17.03 \%$ \\
\hline Marche & $€ 425.50$ & 223,940 & $2.80 \%$ \\
\hline Molise & $€ 335.50$ & 43,592 & $0.55 \%$ \\
\hline Piemonte & $€ 387.50$ & 641,068 & $8.02 \%$ \\
\hline Puglia & $€ 490.70$ & 477,528 & $5.97 \%$ \\
\hline Sardegna & $€ 399.50$ & 220,988 & $2.76 \%$ \\
\hline Sicilia & $€ 446.90$ & 617,608 & $7.72 \%$ \\
\hline Toscana & $€ 494.40$ & 513,036 & $6.42 \%$ \\
\hline Trentino Alto Adige & $€ 350.40$ & 133,732 & $1.67 \%$ \\
\hline Umbria & $€ 387.30$ & 139,904 & $1.75 \%$ \\
\hline Valle d'Aosta & $€ 304.90$ & 19,748 & $0.25 \%$ \\
\hline Veneto & $€ 391.00$ & 720,924 & $9.02 \%$ \\
\hline
\end{tabular}

Source: IVASS-Bollettino Statistico (2015)

On the analysis of the documents produced by the IVASS, the variables from which we obtain the values of the average TPL motor insurance premium are:

- Contractor's age class

- Bonus / Malus Class

- Car thefts in Italian regions

- Number of insurance fraud in Italian regions

\section{Contractor's age class}

The TPL motor insurance premium varies according to the policyholder's age, and there is an inversely proportional relationship between the age and the cost of the insurance premium.

Figure 1 represents the number of TPL motor insurance policies in 2015 by age and the relative national premiums. Age is appropriately divided into the following classes:

- $18-24$

- $25-34$

- $35-44$

- $45-60$

- $60+$ 


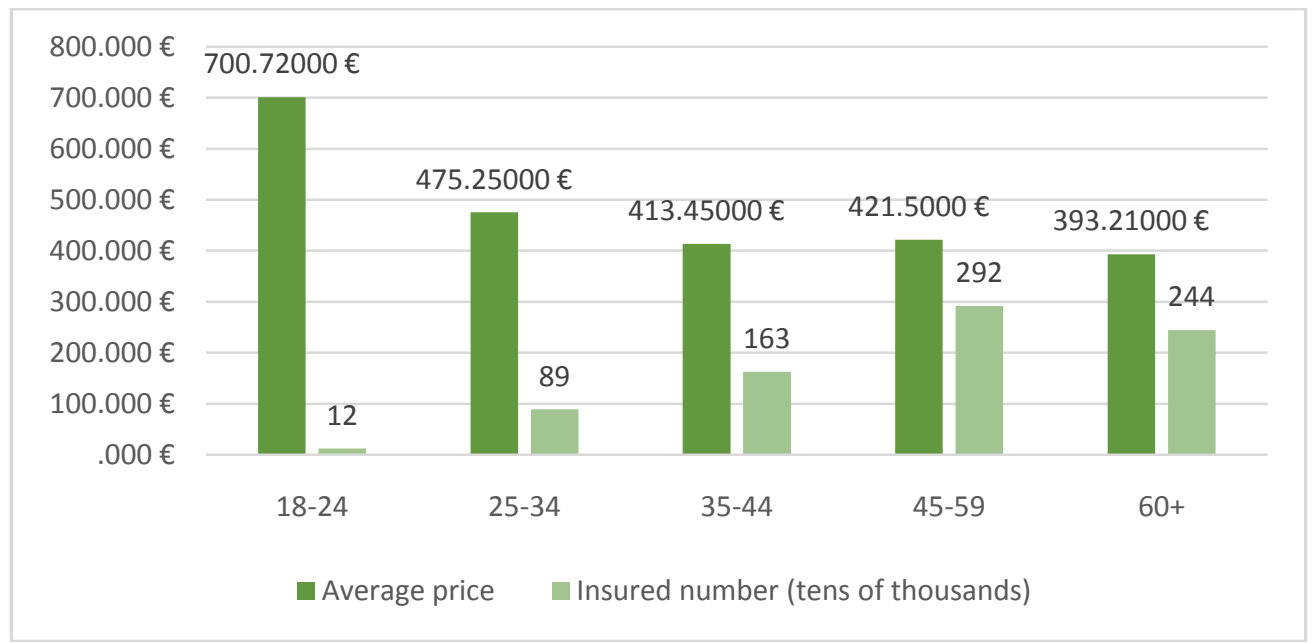

Figure 1: Trend of Contractor's age class, 2015

Source: IVASS Bollettino Statistico (2015)

There is a clear difference between the youngest class (18-24) and the others in terms of number of contractors $(1.46 \%$ of the total, 117,132$)$ and premium $(700.72 €)$. Therefore, to determine the relationship between this parameter and the average cost of TPL motor insurance, it is necessary to determine the prevalence of contractors in Italian regions for each age class. Figures 2 to 5 depict the average premium for the age categories 25-34, 3544, 45-59 and above 60 years, respectively.

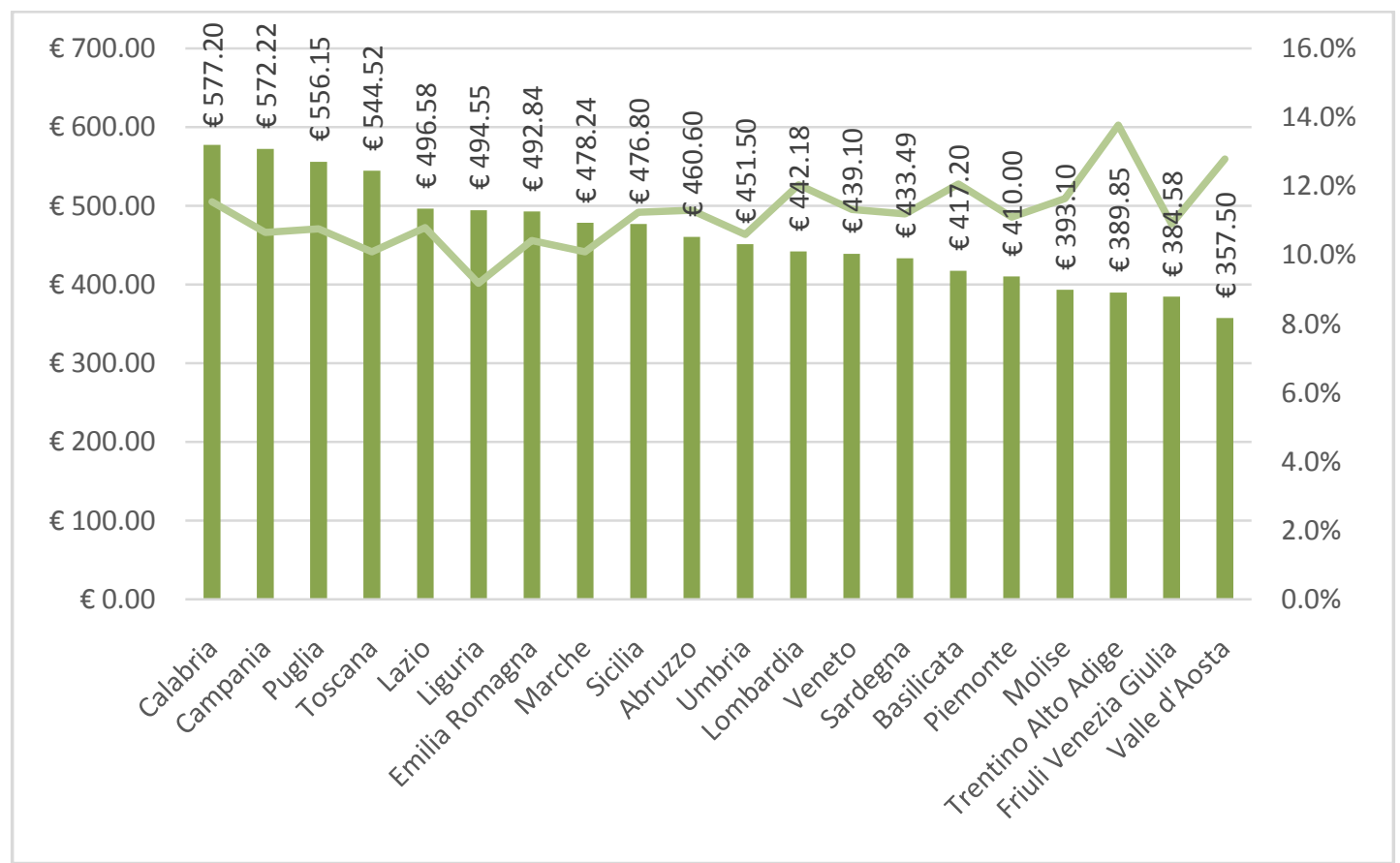

Figure 2: Average premium for age class 25-34 and class weight in the region Source: IVASS Bollettino Statistico (2015) 


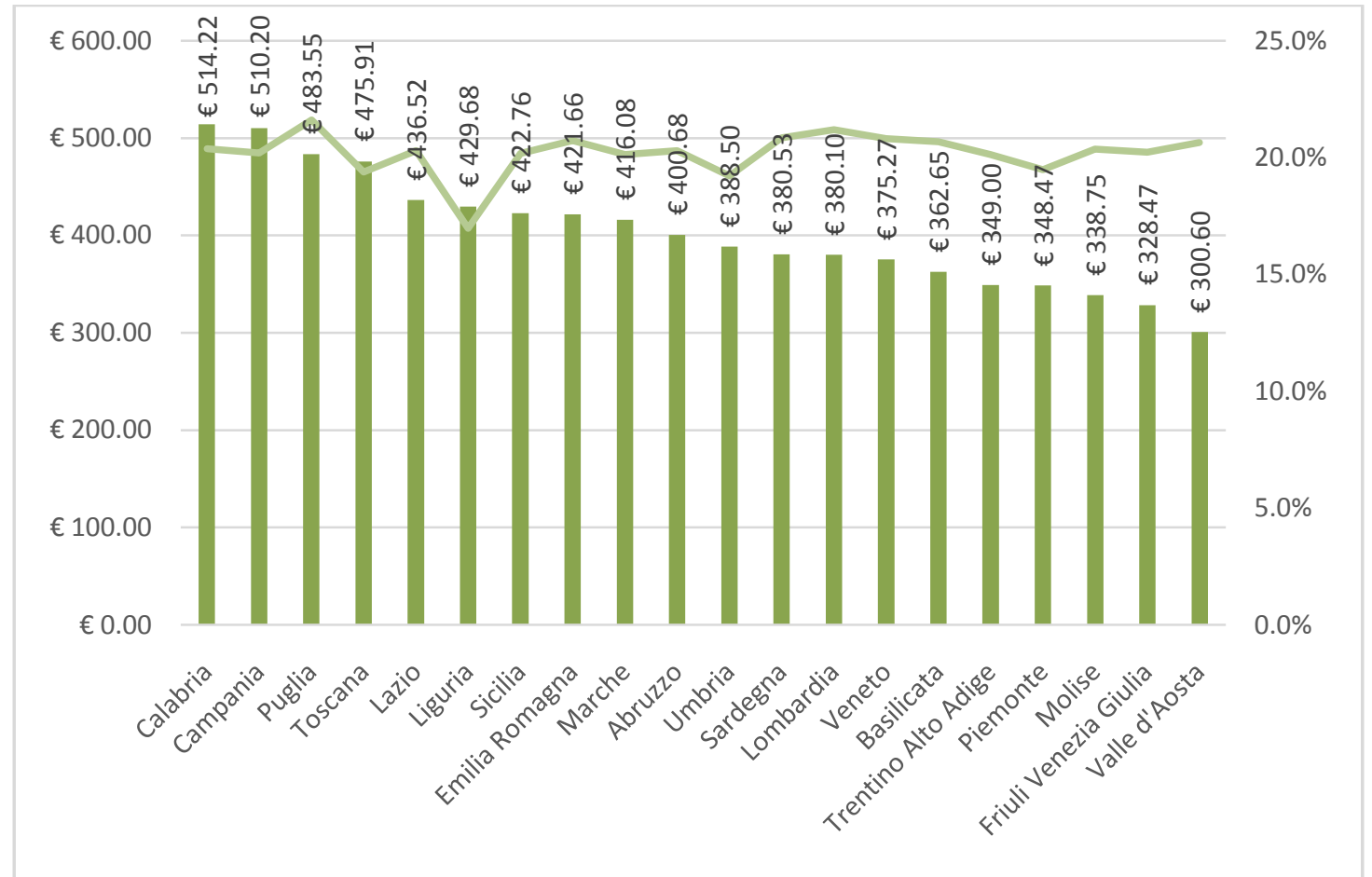

Figure 3: Average premium for age class 35-44 and class weight in the region Source: IVASS Bollettino Statistico (2015)

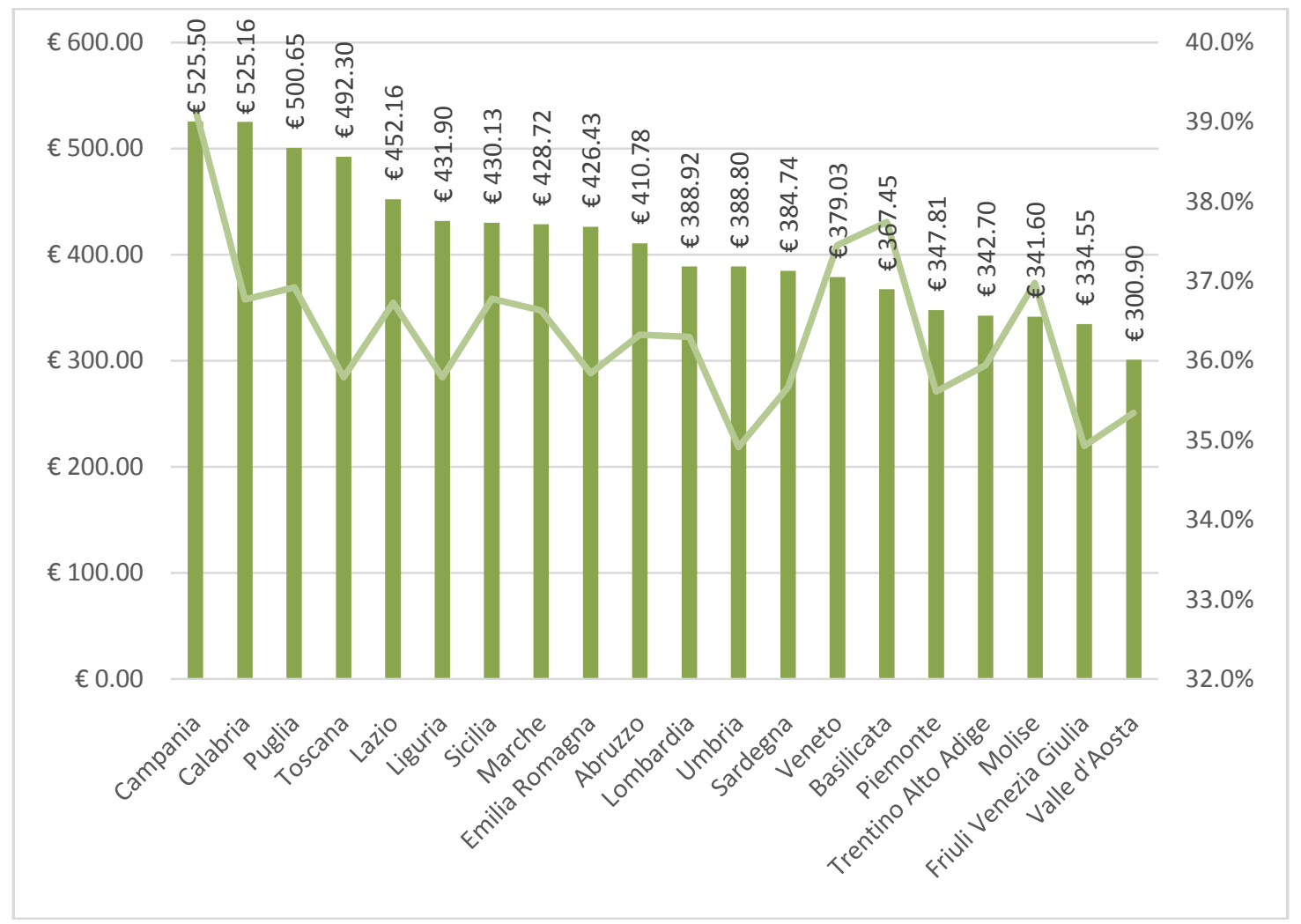

Figure 4: Average premium for age class $45-59$ and class weight in the region Source: IVASS Bollettino Statistico (2015) 


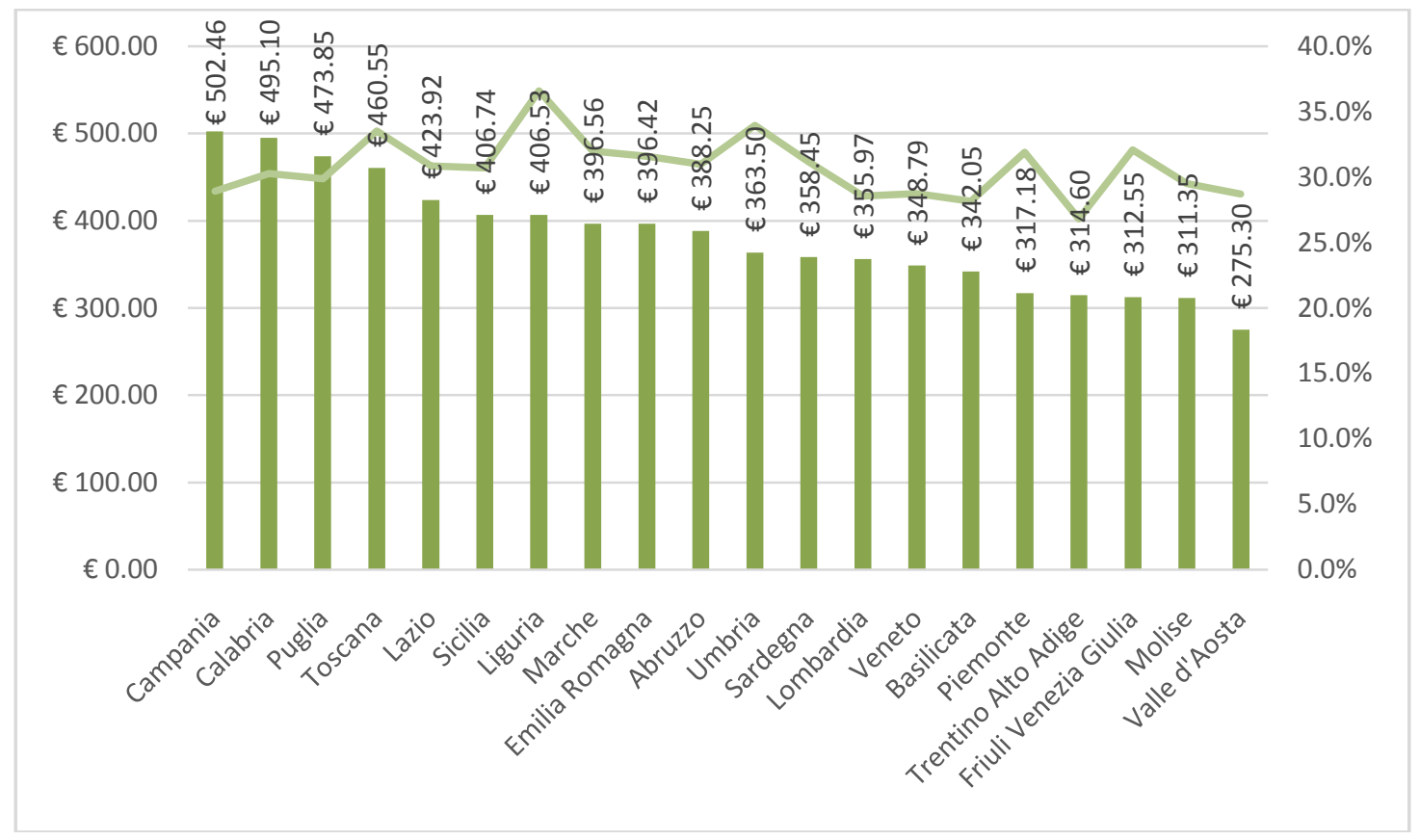

Figure 5: Average premium for age class 60+ and class weight in the region Source: IVASS Bollettino Statistico (2015)

\section{Bonus/malus class}

Bonus / malus clauses are agreements that, in renewing the contract, cause an increase in the premium if the insured has caused accidental damages within a predetermined period (defined as the "observation period") and it decreases if the insured has not caused them during the same period [7]. The bonus-malus clause is based on the following presumption: whoever causes a sin on his own fault is usually a misguided driver and is therefore subject to greater risk. IVASS provides the average premium data for bonus/malus class appropriately divided into four macro-classes: [7]

- Class 1

- Class 2-3

- Class 4-10

- Class 11-18

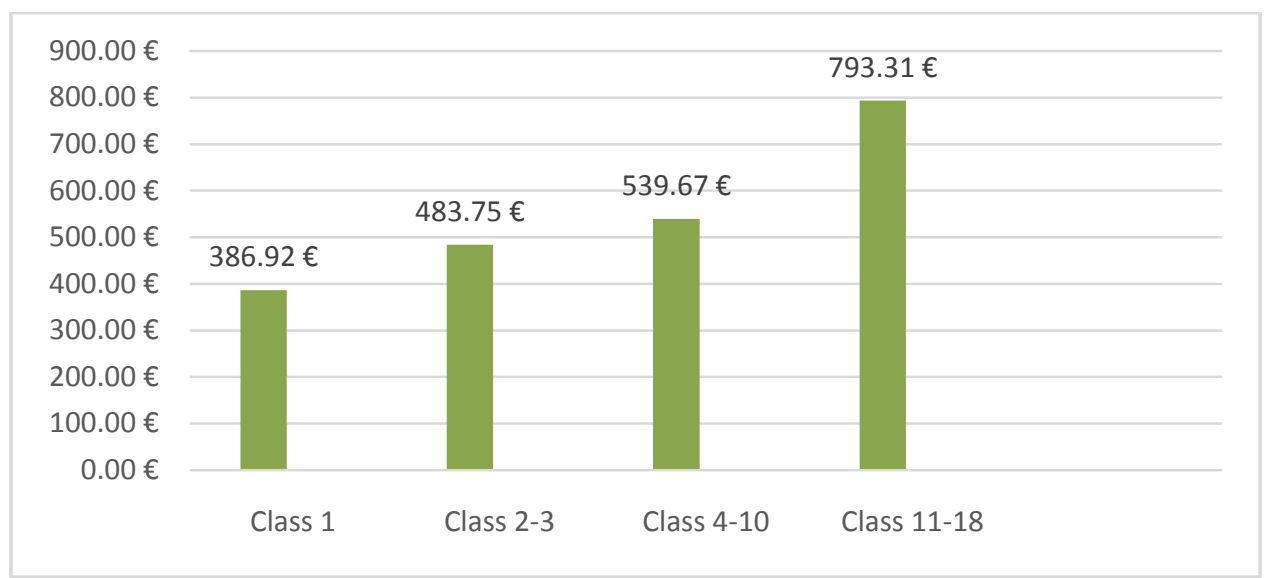

Figure 6: Medium Premium for Bonus Class / Malus, 2015

Source: IVASS BollettinoStatistico (2015) 


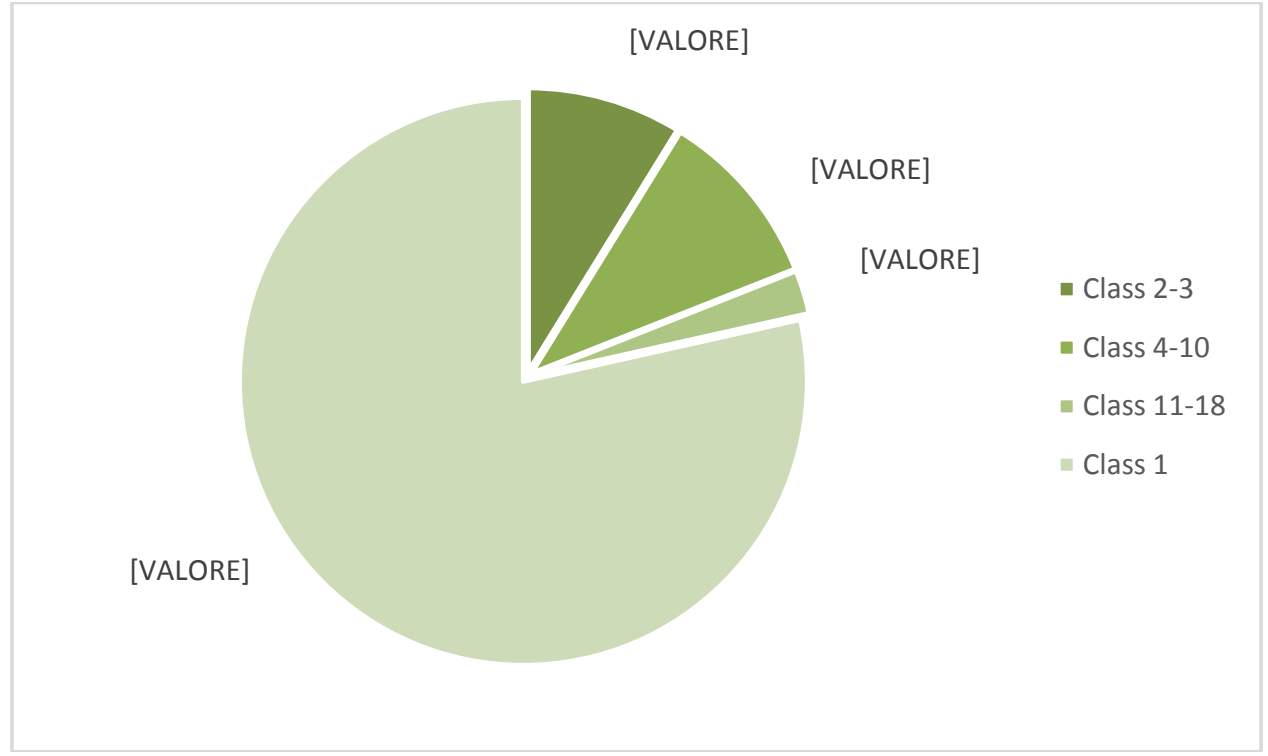

Figure 7: Percentage distribution of bonus/malus classes on the number of contractors Source: IVASS BollettinoStatistico (2015)

Figures 6 and 7 show schematic representations of the medium premium for Bonus Class/Malus, 2015 and the percentage distribution of the same on the number of contractors, respectively.For this parameter is necessary to determine the effects of each class on a regional scale too. See Figures 8 to 11 .

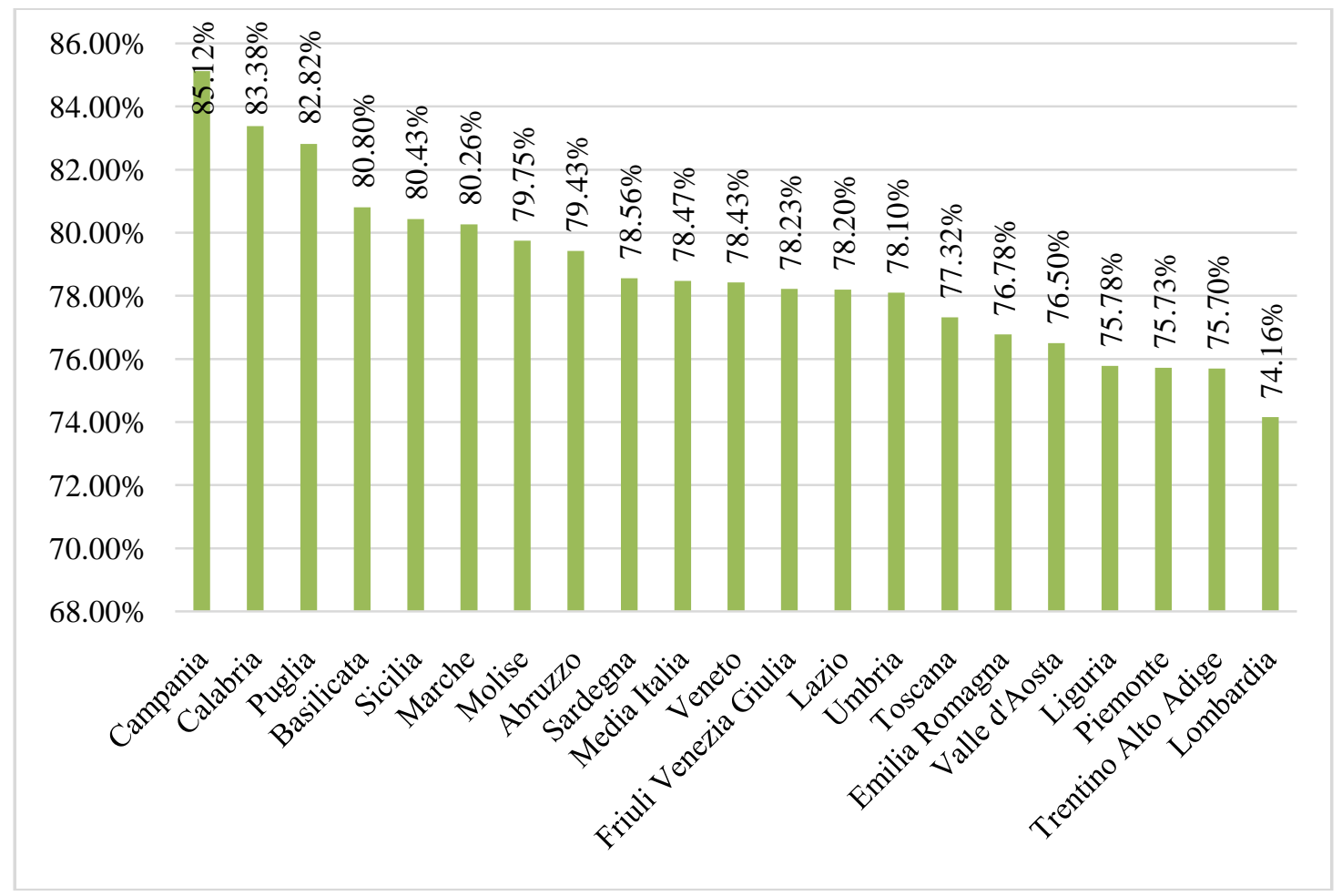

Figure 8: Prevalence of class 1 in Italian regions

Source: IVASS Bollettino Statistico (2015) 


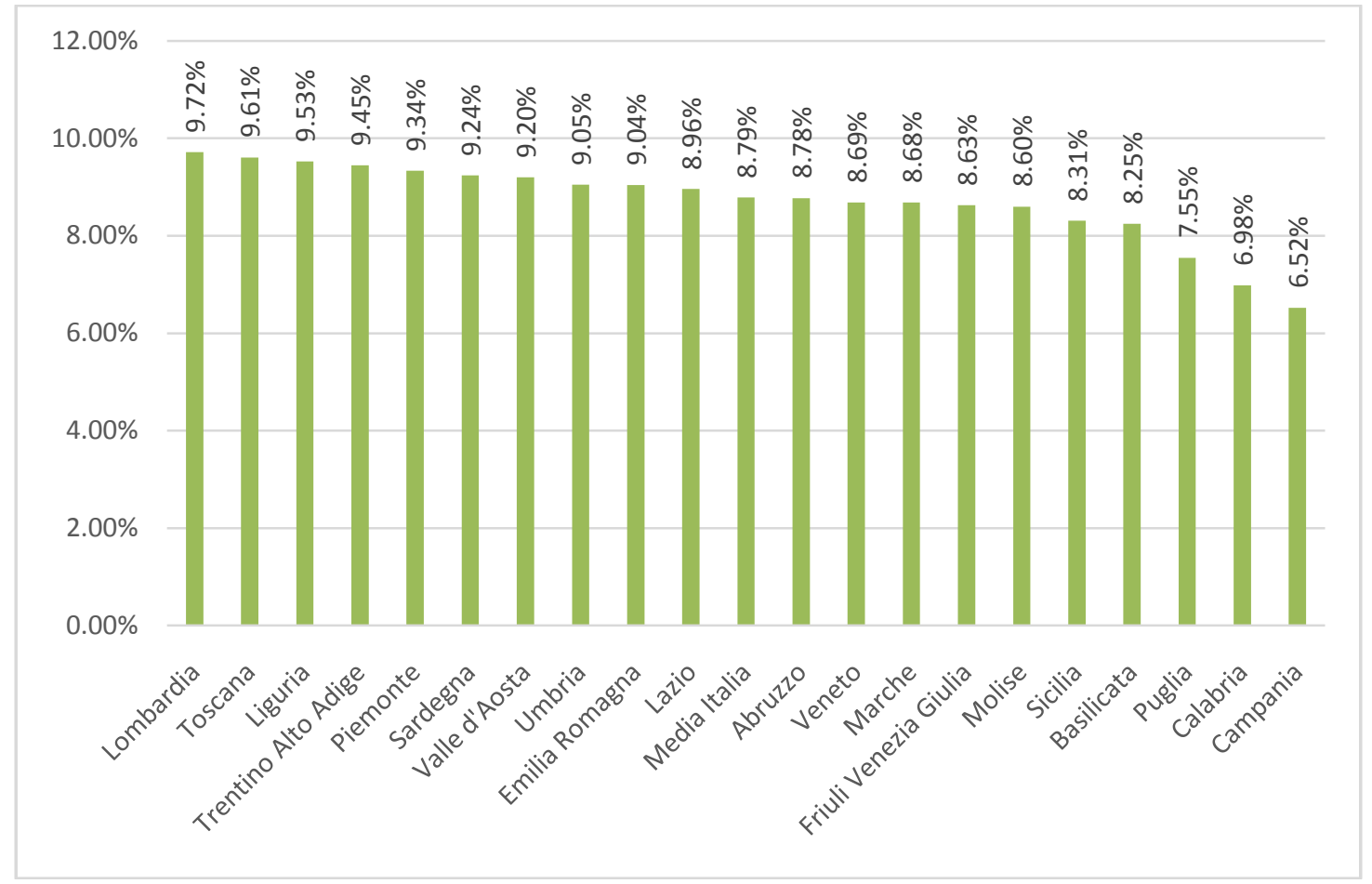

Figure 9: Prevalence of class 2-3 in Italian regions

Source: IVASS Bollettino Statistico (2015)

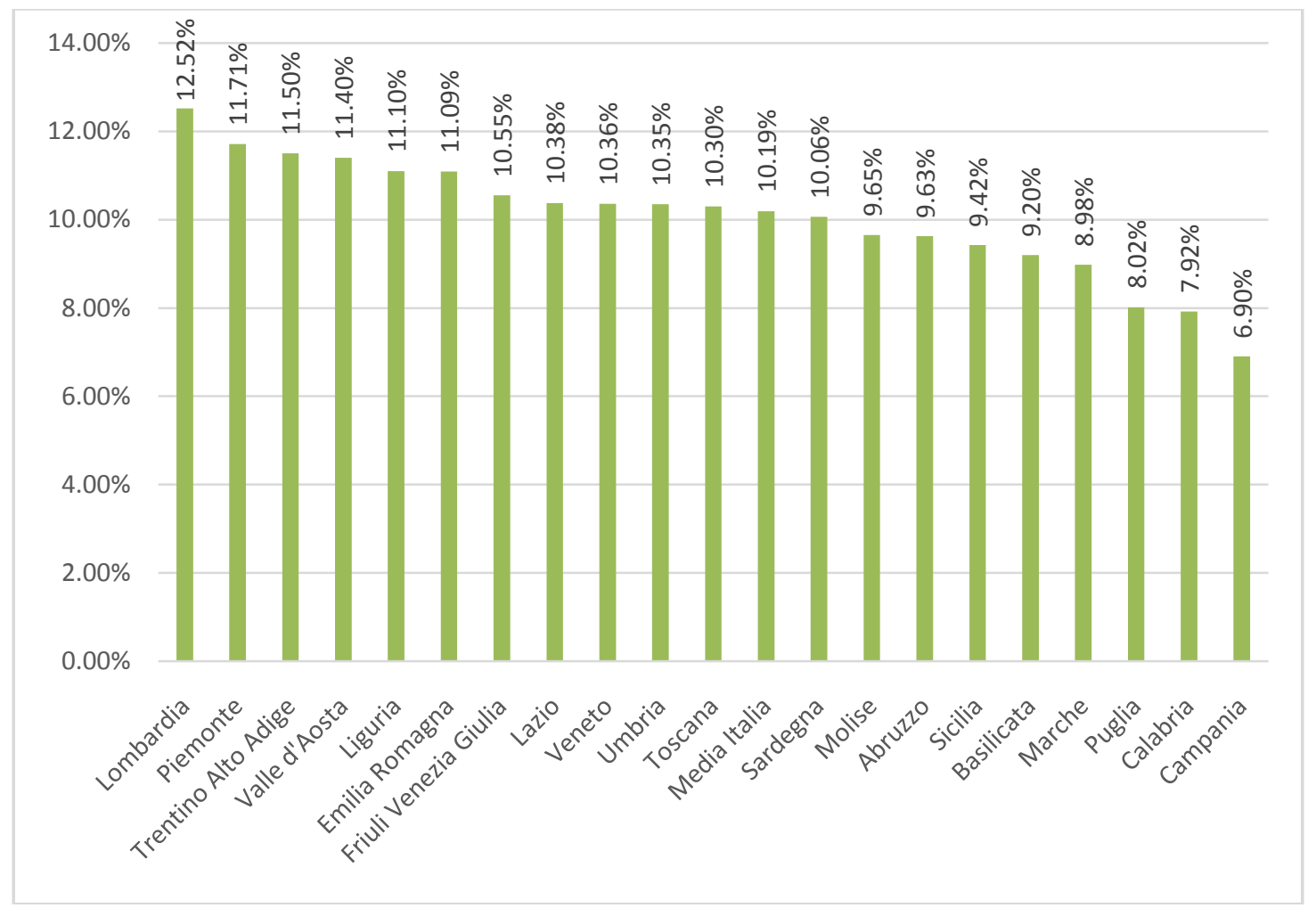

Figure 10: (prevalence of class 4-10 in Italian regions)

Source: IVASS Bollettino Statistico (2015) 


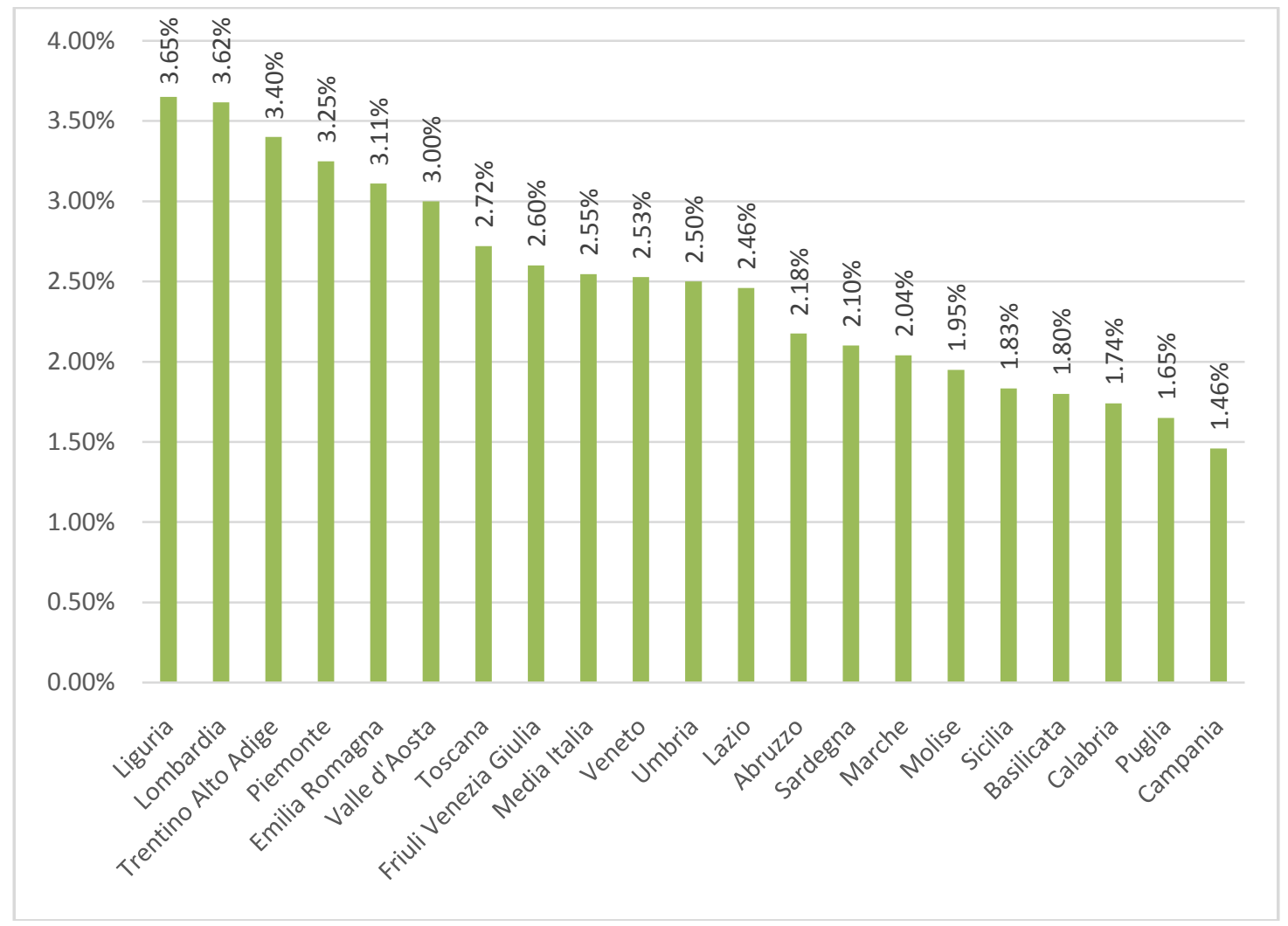

Figure 11: (prevalence of class 11-18 in Italian regions)

Source: IVASS Bollettino Statistico (2015)

\section{Car thefts in Italian regions}

The average premium in the Italian regions also varies depending on the frequency of car theft. To determine more the hazardous geographical areas, the data provided by the Ministry of the Interior concerning the theft of passenger cars registered in Italy in 2015[8] have been used and relativized with the number of vehicle fleets distributed in the various regions [9]. In this way the incidence of car thefts on 1000 cars circulating in each region was obtained. Results are reported in Table 2.

Table 2: Incidence of car thefts on 1000 cars circulating in Italian regions, 2015

\begin{tabular}{|l|l|l|l|}
\hline \multicolumn{1}{|c|}{ Regions } & \multicolumn{1}{|c|}{ Car theft } & \multicolumn{1}{c|}{$\begin{array}{c}\text { Prevalence of circulating cars in } \\
\text { Italy, 2015 }\end{array}$} & \multicolumn{1}{c|}{ Incidence of car theft on 1000 cars circulating } \\
\hline Abruzzo & 1,715 & $2.30 \%$ & 2.02 \\
\hline Basilicata & 397 & $1.00 \%$ & 1.10 \\
\hline Calabria & 3,659 & $3.30 \%$ & 2.99 \\
\hline Campania & 22,136 & $9.00 \%$ & 6.61 \\
\hline Emilia Romagna & 2,776 & $7.40 \%$ & 1.00 \\
\hline Friuli Venezia Giulia & 321 & $2.10 \%$ & 0.41 \\
\hline Lazio & 17,278 & $9.90 \%$ & 4.67 \\
\hline Liguria & 681 & $2.20 \%$ & 0.82 \\
\hline Lombardia & 12,846 & $15.90 \%$ & 2.17 \\
\hline Marche & 787 & $2.70 \%$ & 0.79 \\
\hline Molise & 314 & $0.50 \%$ & 1.54 \\
\hline Piemonte & 5,438 & $7.60 \%$ & 1.91 \\
\hline Puglia & 15,829 & $6.10 \%$ & 7.00 \\
\hline Sardegna & 1,205 & $2.70 \%$ & 1.19 \\
\hline Sicilia & 13,190 & $8.50 \%$ & 4.16 \\
\hline Toscana & 1,795 & $6.40 \%$ & 0.75 \\
\hline Trentino Alto Adige & 179 & $2.40 \%$ & 0.20 \\
\hline Umbria & 438 & $1.70 \%$ & 0.71 \\
\hline Valle d'Aosta & 32 & $0.40 \%$ & 0.22 \\
\hline Veneto & 1,644 & $8.10 \%$ & 0.55 \\
\hline TotaleComplessivo & $\mathbf{1 0 2 , 6 6 2}$ & $\mathbf{1 0 0 . 0 0 \%}$ & $\mathbf{2 . 7 5}$ \\
\hline
\end{tabular}

Source: ASAPS Furti 2015-Dato Nazionale and ACI-Annuario 2016 
Based on the latest definitive data provided by the IVASS for the year 2015[6], it is possible to analyze the incidence of claims exposed to fraud risk. It should be pointed out that "fraud risk" means the risk of an economic loss resulting from the unlawful conduct of insured persons against the insurance undertaking. Claims reported to insurance companies in 2015 amounted to approximately 2.8 million. To determine synthetic indicators comparable between the different geographic areas, the number of claims exposed to fraud identified by insurance companies was related to the number of claims reported in the year.

Table 3: Incidence of number of insurance fraud in Italian regions, 2015

\begin{tabular}{|l|l|l|l|}
\hline Regions & Claims denounced & Claims exposed to fraud risk & Average incidence \\
\hline Abruzzo & 55,235 & 12,138 & 2.02 \\
\hline Basilicata & 18,250 & 4,291 & 1.10 \\
\hline Calabria & 55,731 & 15,662 & 2.99 \\
\hline Campania & 244,430 & 104,811 & 6.61 \\
\hline Emilia Romagna & 208,355 & 41,656 & 1.00 \\
\hline Friuli Venezia Giulia & 45,022 & 7,817 & 0.41 \\
\hline Lazio & 380,244 & 77,877 & 4.67 \\
\hline Liguria & 100,245 & 19,003 & 0.82 \\
\hline Lombardia & 485,746 & 78,645 & 2.17 \\
\hline Marche & 67,940 & 13,359 & 0.79 \\
\hline Molise & 13,202 & 3,894 & 1.54 \\
\hline Piemonte & 224,341 & 40,816 & 1.91 \\
\hline Puglia & 128,503 & 36,018 & 7.00 \\
\hline Sardegna & 66,353 & 11,407 & 71.19 \\
\hline Sicilia & 194,517 & 44,280 & 4.16 \\
\hline Toscana & 201,100 & 37,485 & 0.75 \\
\hline Trentino Alto Adige & 50,750 & 9,505 & 0.20 \\
\hline Umbria & 42,073 & 7,501 & 0.71 \\
\hline Valle d'Aosta & 8,611 & 1,257 & 0.22 \\
\hline Veneto & 199,603 & 30,435 & 0.55 \\
\hline TotaleComplessivo & $\mathbf{2 , 7 9 0 , 2 5 0}$ & $\mathbf{5 9 7 , 8 5 7}$ & $\mathbf{2 . 7 5}$ \\
\hline
\end{tabular}

\section{One model for TPL motor insurance: the multiple linear regressions}

\section{The research methodology}

The work uses a multiple linear regression model (Nelder and Wedderburn, 1972) to analyze the dependency relationship between a variable $\mathrm{Y}$, which is configured as a dependent variable or response, and some independent variables that affect it, called explanatory variables. The equation representing the multiple linear regression model is as follows: $y_{i}=\beta_{0}+\beta_{1} x_{i 1}+\beta_{2} x_{i 2}+\cdots+\beta_{p} x_{i p}+\varepsilon_{i} i=1, \ldots, n$

Where $\mathrm{n}$ represents the total number of observations and $\mathrm{p}$ is the number of explanatory variables, $\epsilon_{i}$ is the error at observation $i$ and it is assumed that it is i.i.d. (Independent and identically distributed); it is normally distributed with mean 0 and variance $\sigma^{2}$. Using the ordinary least squares method as the optimization criterion, the estimated values $\beta_{0}, \beta_{1}, \ldots, \beta_{p}$ are obtained.

To ensure the model is properly specified and functioning correctly and that the regression coefficient obtained through the least squared method is stable after applying the regression model, the variance inflation factor (VIF) was calculated (O'Brien, 2007). It quantifies how much the variance is inflated and therefore helps to detect multicollinearity in a set of multiple regression variables (Craney \& Surles, 2002).

The study was carried out using several distinct steps:

1. Creation of the model and therefore the choice of the independent variables

2. Checking the linearity constraint between the dependent and independent variables. For this purpose, the correlation matrix is calculated and the independent variables with the significant correlation coefficient are included in the model. In addition, to measuring the significance between the $y$ variable and each variable $x_{i}$, we calculate: 
- Standard error (a small standard error implies a more reliable prediction)

- The student's $t$ value to verify the statistical significance level of the data used.

3. Statistical control of the entire model. To this end we calculate:

- coefficient of determination $\mathrm{R}^{2}$ (Nagelkerke, 1991), which allows us to estimate the goodness of the model produced;

- the F test (Mehta and Patel,1983), evaluating whether there is a significant relationship between the dependent variable and the set of explanatory variables;

- evaluating VIF if there is correlation among the predictors.

\section{Discussion}

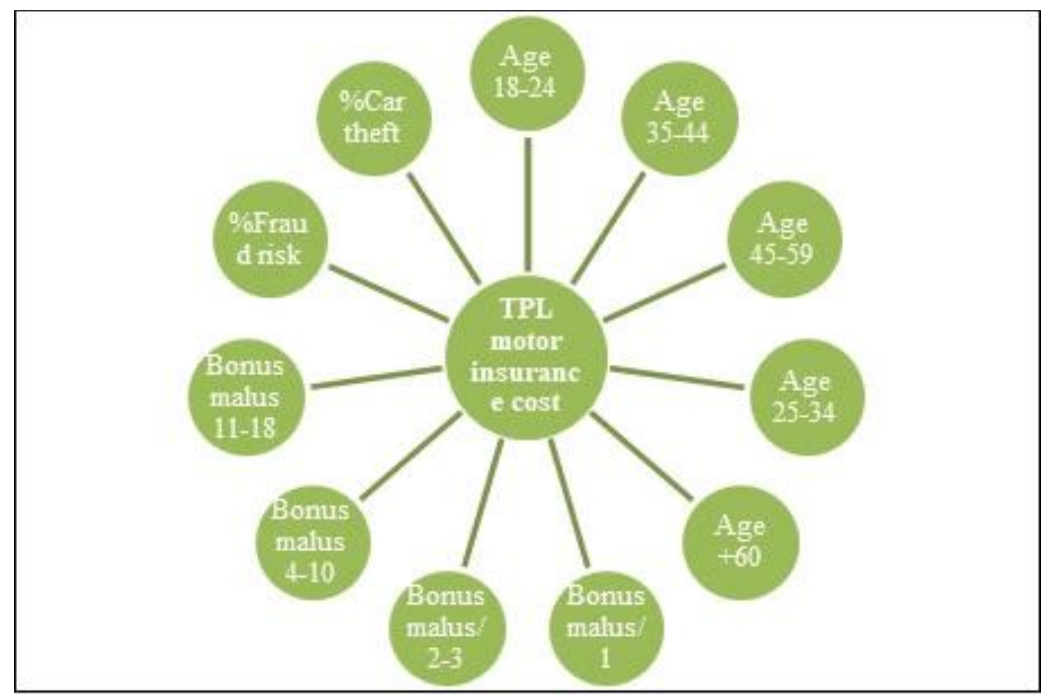

Figure 12: Relational model of the blocks included in the analysis

The dependence structure between a dependent variable and a set of explanatory variables has been studied through a statistical tool XLStat, applied to data written in matrix form.Firstly, the correlation matrix was calculated, where it was possible to observe the degree of correlation that exists between all the variables involved, regardless of their dependent or explanatory function.

Table 4: Correlation matrix

\begin{tabular}{|l|l|l|l|l|l|l|l|l|l|l|l|l|}
\hline Correlationmatrix & $\begin{array}{l}18- \\
24\end{array}$ & $\begin{array}{l}25- \\
34\end{array}$ & $\begin{array}{l}35- \\
44\end{array}$ & $\begin{array}{l}45- \\
59\end{array}$ & +60 & $\begin{array}{l}\text { Bonus } \\
\text { malus/ } \\
1\end{array}$ & $\begin{array}{l}\text { Bonus } \\
\text { malus/ } \\
2-3\end{array}$ & $\begin{array}{l}\text { Bonus } \\
\text { malus/ } \\
4-10\end{array}$ & $\begin{array}{l}\text { Bonus } \\
\text { malus/ } \\
11-18\end{array}$ & $\begin{array}{l}\text { \% } \\
\text { Fraud } \\
\text { risk }\end{array}$ & $\begin{array}{l}\text { \% } \\
\text { Car } \\
\text { theft }\end{array}$ & $\begin{array}{l}\text { Average } \\
\text { premium }\end{array}$ \\
\hline $18-24$ & $\mathbf{1}$ & 0.69 & -0.02 & -0.35 & -0.39 & -0.63 & 0.49 & 0.66 & 0.66 & -0.43 & -0.51 & -0.62 \\
\hline $25-34$ & 0.70 & $\mathbf{1}$ & 0.50 & 0.02 & -0.84 & -0.15 & 0.06 & 0.23 & 0.09 & -0.12 & -0.17 & -0.52 \\
\hline $35-44$ & -0.02 & 0.50 & $\mathbf{1}$ & 0.29 & -0.760 & 0.28 & -0.302 & -0.20 & -0.39 & 0.11 & 0.29 & -0.08 \\
\hline $45-59$ & -0.35 & 0.02 & 0.29 & $\mathbf{1}$ & -0.483 & 0.69 & -0.703 & -0.68 & -0.60 & 0.76 & 0.61 & 0.53 \\
\hline+60 & -0.40 & -0.84 & -0.76 & -0.48 & $\mathbf{1}$ & -0.20 & 0.286 & 0.11 & 0.22 & -0.22 & -0.18 & 0.19 \\
\hline Bonus malus/1 & -0.63 & -0.15 & 0.28 & 0.69 & -0.197 & $\mathbf{1}$ & -0.948 & -0.99 & -0.93 & 0.82 & 0.65 & 0.56 \\
\hline Bonus malus/ 2-3 & 0.49 & 0.06 & -0.30 & -0.70 & 0.286 & -0.95 & $\mathbf{1}$ & 0.91 & 0.81 & -0.84 & -0.68 & -0.55 \\
\hline Bonus malus/ 4-10 & 0.67 & 0.23 & -0.20 & -0.68 & 0.110 & -0.99 & 0.910 & $\mathbf{1}$ & 0.92 & -0.81 & -0.63 & -0.61 \\
\hline Bonus malus/ 11-18 & 0.67 & 0.09 & -0.39 & -0.60 & 0.220 & -0.93 & 0.806 & 0.92 & $\mathbf{1}$ & -0.67 & -0.55 & -0.39 \\
\hline \% Fraud risk & -0.43 & -0.12 & 0.11 & 0.75 & -0.220 & 0.82 & -0.842 & -0.81 & -0.67 & $\mathbf{1}$ & 0.72 & 0.62 \\
\hline \% car theft & -0.51 & -0.17 & 0.29 & 0.61 & -0.184 & 0.65 & -0.683 & -0.63 & -0.55 & 0.72 & $\mathbf{1}$ & 0.73 \\
\hline Average premium & -0.62 & -0.52 & -0.09 & 0.53 & 0.188 & 0.56 & -0.549 & -0.61 & -0.39 & 0.62 & 0.73 & $\mathbf{1}$ \\
\hline
\end{tabular}

The analysis of the correlation matrix shows that the average premium of TPL motor insurance, is particularly related, among other variables, to the fraud risk and the incidence of car thefts on 1,000 carscirculating in a positive sense (correlation indices equal to 0.623 and 0.731 , respectively) and, in a negative sense, to the variables Age 18-24 and Bonus Malus / Class 11-18. 
After the correlation matrix, the parameters of the model were estimated and then normalized to have a greater readability and interpretation of the model itself (Standard errors, the student's $t$ value and the corresponding pvalue).

Table 5: Parameters of the model

\begin{tabular}{|l|l|l|l|l|}
\hline \multirow{2}{*}{ Variables } & \multicolumn{4}{l}{ Coefficients } \\
\cline { 2 - 5 } & Values & Standard errors & t & p-value \\
\hline Intercept & $58,234.912$ & $33,129.647$ & 1.758 & 0.113 \\
\hline Age 18-24 & $-5,5,18.019$ & $3,889.254$ & -1.419 & 0.190 \\
\hline Age 25-34 & $1,804.876$ & $2,145.829$ & 0.841 & 0.422 \\
\hline Age 35-44 & -688.510 & $1,437.031$ & -0.479 & 0.643 \\
\hline Age 45-59 & $1,088.777$ & $1,246.412$ & 0.874 & 0.405 \\
\hline Age +60 & 0.000 & 0.000 & & \\
\hline Bonus-Malus/Class 1 & $-5,7784.710$ & $32,968.898$ & -1.753 & 0.114 \\
\hline Bonus-Malus/Class 2-3 & $-57,596.264$ & $34,625.694$ & -1.663 & 0.131 \\
\hline Bonus-Malus/Class 4-10 & $-65,681.751$ & $33,307.122$ & -1.972 & 0.080 \\
\hline Bonus-Malus/Class 11-18 & $-41,322.916$ & $31,542.106$ & -1.310 & 0.223 \\
\hline \% fraud-risk & -343.745 & 322.023 & -1.067 & 0.314 \\
\hline \%car-theft & $20,081.427$ & $6,769.621$ & 2.966 & 0.016 \\
\hline
\end{tabular}

Table 6: Normalized parameters of the model

\begin{tabular}{|l|l|l|l|l|}
\hline \multirow{2}{*}{ Variables } & \multicolumn{2}{l}{ Normalized coefficients } & t & p-value \\
\cline { 2 - 5 } & Normalized values & Standard errors & & \\
\hline Intercept & & & & \\
\hline Age 18-24 & -0.468 & 0.330 & -1.419 & 0.190 \\
\hline Age 25-34 & 0.262 & 0.311 & 0.841 & 0.422 \\
\hline Age 35-44 & -0.095 & 0.197 & -0.479 & 0.643 \\
\hline Age 45-59 & 0.159 & 0.182 & 0.874 & 0.405 \\
\hline Age +60 & 0.000 & 0.000 & & \\
\hline Bonus-Malus/Class 1 & -23.478 & 13.395 & -1.753 & 0.114 \\
\hline Bonus-Malus/Class 2-3 & -7.093 & 4.264 & -1.663 & 0.131 \\
\hline Bonus-Malus/Class 4-10 & -13.218 & 6.703 & -1.972 & 0.080 \\
\hline Bonus-Malus/Class 11-18 & -4.049 & 3.090 & -1.310 & 0.223 \\
\hline \% fraud-risk & -0.326 & 0.306 & -1.067 & 0.314 \\
\hline \%car-theft & 0.592 & 0.200 & 2.966 & 0.016 \\
\hline
\end{tabular}

The regression model shows how the average premium strongly depends on the variable the incidence of car thefts on 1.000 cars circulating ( $\mathrm{p}$-value $=0.016$ ). Therefore, the multiple regression model is obtained as follows:

TPL-motor-insurance-cost $=58,234.912-5,518.019 *$ Age18-24 + 1,804.876*Age25-34 - 688.510*Age35-44 + 1,088.777*Age45-59 - 57,784.710* Bonus-Malus/Class1 - 5,7596.264* Bonus-Malus/Class2-3 - 65,681.751* Bonus-Malus/Class4-10 - 41,322.916* Bonus-Malus/Class11-18 - 343.745*\%fraud-risk + 20,081.427*\%cartheft

Where, 58,234.912 represents the intercept, which corresponds to the mean value of the dependent variable Y when the explanatory variables $X$ are equal to 0 (paradoxically); the sign of the single $\beta$ indicates whether the linear relationship with the dependent variable is positive or negative.

In the third step of analysis two coefficients were calculated to estimate the goodness of model: 
- Coefficient of determination $\mathrm{R}^{2}$ represents the proportion of $\mathrm{Y}$ variability explained by the explanatory variables and it is obtained from the ratio between the sum of the squares of the regression (SQR) and the sum of the squares (SQT).

$$
r_{Y}^{2}=\frac{S Q R}{S Q T}
$$

Through statistical tool the coefficient of determination of the constructed model is equal to 0,889 and, therefore, $88,79 \%$ of the variability of the average premiums of TPL motor insurance is explained by the selected explanatory variables.

- The variance inflation factor is a measure of how much the variance of the estimated regression coefficient $\beta_{p}$ is "inflated" by the existence of correlation among the predictor variables in the model.

$$
V I F_{\beta_{p}}=\frac{1}{1-r_{p}^{2}}
$$

Where, $r_{p}^{2}$ is the $r^{2}$-value obtained by regressing thepth predictor on the remaining predictors.

From the results obtained all $V I F_{\beta_{p}}$ (Table 8) are minus 1 and this means that there is no correlation among the $p t h$ predictor and the remaining predictor variables, and hence the variance of $\beta_{p}$ is not inflated at all.

Table 7: Predictor variables $\left(V I F_{\beta_{p}}\right)$

\begin{tabular}{|l|l|}
\hline \multicolumn{1}{|c|}{$\boldsymbol{V I F}_{\boldsymbol{\beta}_{\boldsymbol{p}}}$} & \\
& \\
\hline Age 18-24 & \\
\hline Age 25-34 & 0,119 \\
\hline Age 35-44 & 0,107 \\
\hline Age 45-59 & 0,043 \\
\hline Age +60 & 0,036 \\
\hline Bonus-Malus/Class 1 & 0 \\
\hline Bonus-Malus/Class 2-3 & 0,231 \\
\hline Bonus-Malus/Class 4-10 & 0,056 \\
\hline Bonus-Malus/Class 11-18 & 0,560 \\
\hline \% fraud-risk & 0,531 \\
\hline \%car-theft & 0,103 \\
\hline
\end{tabular}

\section{Conclusion}

In Italy, during the year 2015, 7,995,744 Motor TPL policies were subscribed with an average premium of $€$ 439.10 (50\% of policyholders pay more than $€ 397,90 \%$ of policyholders pay less than $€ 679$ and only $10 \%$ of the insured less than $€ 247$ ). Furthermore, there are differences in the value of the premium on the national territory in which Campania is the leader, with an average premium of approximately $€ 586$ more than $33.43 \%$ compared to the national average; this is followed almost similarly by Calabria ( $€ 499+13.7 \%)$, Tuscany $(€ 494+12.6 \%)$, Puglia $(€ 491+11.8 \%)$ and Lazio $(€ 487+10.8 \%)$. Around the national averages are Sicily $(€ 447+1.8 \%)$, Liguria ( $€ 435+1.3 \%)$, Romagna (€ $433-1.4 \%$ ) and Marche (€ 426, -3.1\%) [6].

The analysis also shows an evident disparity between the younger class (18 - 24) and the others both in terms of number of contractors $(1.46 \%$ of the total, 117,132) and in terms of premium $(€ 700.72)$. The largest class of contractors is between 45 and 59 years $(36.55 \%, 2,922,728)$, who are those who benefit from the penultimate average premium in decreasing amounts ( $€ 421.50)$, followed by contractors with age greater than or equal to 60 $(30.51 \% ; 2,439,892)$, which pay an average premium of $€ 393.21$, the lowest average premium among the classes. The rankings are closed by contractors between the ages of 35 and $44(20.39 \%, 1,630,108$, average premium of $€$ 413.45) and contractors between the ages of 25 and 34 (11.08\%, 885,884, average premium of $€ 475.25)$. 
But what emerges from the regression model realized is that unfortunately, the price of motor TPL insurance is strongly influenced by car thefts. In Italy the number of car thefts in 2015 was 102,660. In absolute terms, Campania holds the sad record of the Italian region in which the greatest number of car thefts is perpetrated $(22,136)$. The disgraceful podium is completed by Lazio (17,278 thefts) and Puglia $(15,829$ thefts). Thefts in the 3 regions listed above represent more than half of the thefts occurring throughout the country (54\%).

These findings confirm that lower cost of the motor TPL insurance is necessary to define, in Italy, a policy that combats the phenomenon of car thefts and insurance fraud, issue suitable guidelines for insurance companies and introduce mandatory regulations forcing companies to effectuate product reformulation.

\section{Bibliografy}

Decree Law No.223 (2006). Gazzetta Ufficiale General serie - n. 153-2006.

Decree Law No 31 (2007). Gazzetta Ufficiale General serie - n. 27-2007

Cottone N. (2007). L'ABC del decreto sulle liberalizzazioni. Il Sole24ore.com.

Cerchiai F.(2010). Primo piano polizze RC Auto parla il presidente dell'ANIA. Il Mondo.

Fabio Cerchiai (2010). Ancora sulla RC Auto. Conference of the Cesar Foundation. http://www.ania.it.

IVASS Bollettino Statistico (2015). L'andamento dei prezzi effettivi per la garanzia r.c. auto. http://www.ivass.it.

ISVAP regulation n.16 (2008). Costruzione della tariffa tecnica nell'RCAutoASAPS Furti 2015-Dato Nazionale http://www.asaps.it.

ACI Annuario $2016 \mathrm{http}: / /$ www.aci.it.

O'Brien, Robert. (2007). A Caution Regarding Rules of Thumb for Variance Inflation Factors. Quality \& Quantity. 41. 673-690. 10.1007/s11135-006-9018-6.

Trevor A. Craney\& James G. Surles (2002), Model-Dependent Variance Inflation Factor Cutoff Values, Quality Engineering. 14(3): 391-403. http://dx.doi:10.1081/QEN-120001878Tomeski (2012) ù

Lili Bao1 \&Zhengyu Gu (2014). A Study of the Deficit of the Third Party Liability Compulsory Insurance of Motor Vehicle. Accounting and Finance Research, Vol. 3, No.1: 116-120. http://dx.doi.org/10.5430/afr.v3n1p116

J. A. Nelder and R. W. M. Wedderburn (1972). Generalized Linear Models. Journal of the Royal Statistical Society. Series A (General), Vol. 135, No. 3: 370-384

N. J. D. NagelkerkeBiometrika (1991). A Note on a General Definition of the Coefficient of Determination. Vol. 78, No. 3:691-692.

B. Tomeski (2012). Development of Motor Third Party Liability Insurance. Procedia-Social and Behavioral Sciences. Vol. 44: 200 - 209.

Insurance Europe (2015). European Motor Insurance Markets. www.insuranceeurope.eu

S. Gönülal (2010). Motor Third-Party Liability Insurance. The World Bank. www.worldbank.org/nbfi

A. Santoliquido (2014). L'assicurazione automobilistica in Italia: le ragioni di un'«anomalia». Economia dei Servizi. Vol. 2: pp. 161-178. http://dx.doi: 10.2382/80878

Boston Consulting Group (2014). Confronto sul mercato RCA in Europa. www.ania.it

Mehta C.R.; Patel N.R. (1983). A Network Algorithm for Performing Fisher's Exact Test in r Xc Contingency Tables. Journal of the American Statistical Association. 78(382): 427-434. http://dx.doi:10.2307/2288652 